\title{
Effect of strategic intelligent games on gathering attention
}

\author{
Margrit Yeşiltepe ${ }^{1}$, and Gülşen Altıntaş ${ }^{2 a}$ \\ ${ }^{1}$ Yildiz Technical University Education Programs and Teaching Department Non-Thesis Master's \\ Program, Istanbul, Turkey \\ ${ }^{2}$ Academician at Education Programs and Teaching Department, Celal Bayar University, \\ Demirci/Manisa. Turkey
}

\begin{abstract}
Nowadays, while raising the humans of information age, to which extent we can provide guidance under the roof of the school that will ensure them to tackle the problems that they will encounter in the future? Currently, to what extent do we assume our children whom we prepare for currently unknown professions of future ages the name, function and the requirements for equipment of which are not known by us now, for their future, country and the world will have what degree of strategic thinking skills and whether they will be attentive in case of confusion regarding the target. If we assume that the individuals who will keep pace with rapidly changing world and direct it should have very good level of attention, activities to improve it should be arranged. We should consider making foundations available for them to manage daily problems or possible obstacles by using different thinking methods and by managing them with the plans $\mathrm{a}, \mathrm{b}$ even $\mathrm{c}$ prepared by them, and finding alternative responses in the competition environment and creating added value for them, their country and the world. For this purpose, increase in attention gathering level at the beginning of mental activities would positively affect this process. What would be the effect of plays in developing attention giving and gathering features that are not felt more until coming to the school age? Our study started with this question and the voluntarily participated students were observed during the study. Study covers 3 students playing at very low, middle and high frequency who are selected among universe of 10 students, 2 of which were girls who are the members of strategic mind games activities which is a working group indicating maximum diversity. Subject who are taken under the scope of the study are selected from upper socio-cultural level. Students were expected to participate in thinking skills developing paper-and-pencil activities and strategic mind games. Strategy developing games that are used in the study are used for development of gathering attention.
\end{abstract}

Keywords: Game; attention

\footnotetext{
a Corresponding author: gulsencbu@gmail.com
} 


\section{Introduction}

There are many unsuccessful students in the school life despite absence of certain mental, physical or psychological causes. Failure of big portion of these students may be caused by attention problem, hyper activity or learning problems in certain fields (such as reading, writing and mathematics).

What a child remembers about what a child sees, hears, reads and does is directly proportionate to the attention and this skill is a basic element for success of a child. If it is made a habit in early ages, success in school life is inevitable. This feature will teach the child the discipline and reaching the targets. Learning of children who can fully gather their attention on a study is at upper levels compare to those children who cannot show that success. In order to make an effective learning, the attention should be gathered on the subject. As soon as attention is gathered on a subject, almost all subjects can be understand and comprehended. However, learning and using attention is quite difficult. Inability to gather the attention on a subject is a problem involving education and the children can be taught to gather their attention on a subject by making practices.

Toys teach: Paper plays etc. teach concentration. Plays such as quoits develop their abilities and concentration skills [1].

Children generally find some learning and skill development types annoying. Learning takes place rapidly when excite and exploration are felt. Therefore, toys have special importance to keep the interest of child alive while acquiring required skills [1].

In order to learn a material, first of all attention should be paid to that material. This process is involves the processes of gathering, concentrating and continuance of attention. Attention is the first step of the learning process. We cannot comprehend, learn or remember anything to which we do not pay our attention. One of the important features that is required to be focused on in teaching is to ensure concentration on the behaviors to which the attention is aimed and to keep that concentration for longer time in a awakened manner.

Attention can be defined as the process of processing limited number of information among many number of information that can be reached by our sense organs, our memory and other cognitive processes. Considering under the context of that definition, attention is selection of a critical one among many internal and external stimulants sets to subject it to further analysis. There are some limits in our mental resources and amount of information that we can concentrate at a certain time is limited. Attention provides us with the possibility of using our limited sources wisely. Therefore, it is a critical process to determine which information will be selected among information coming from many external stimulants; our attention decides that and how much of our sources will be used in order to process that information.

Play is important in terms of mental and motor development of children. Play gives the possibility for children to explore the world surrounding them and to reach in individual manner.

With intelligent games, students will recognize their abilities and potentials in their individual works and group works, they will develop and enhance self esteem, gain systematic and disciplined study habits for success and they will develop the attitudes and behaviors of creating alternative solutions and strategies fearlessly in case of failure. For a child, play is the mirror of real life. Children learn sharing, relations between humans, conflicts, causes and consequences of disagreements, making decisions, solving problems and understand the surroundings during the play. Plays have significant contribution in mental development of children. Mental development is relevant to comprehending and keeping information. With all that, decision making, thinking, evaluation, commenting abilities of children also develop. Attention, perception and thinking functions play important role in successfully planning the game. While the children play, their many 
cognitive abilities also develop. Decision making, memory, strategy, observation, spatial reasoning, problem solving and creating thinking are some of these important cognitive abilities.

"Increasing the attention" for a person experiencing learning problem means for that person to start the work while performing an activity relevant to learning, to direct mental energy towards that activity during the activity and to resist to surrounding distracters [3].

\subsection{Problem Phrase}

Basic problem phrase of the study is "what is the effect of strategic intelligence games on the level of gathering attention?"

Sub problems created depending on that problem are as below;

1.1.1.Are individual and group activities performed effective on the attention?

1.1.2.Are individual and group activities performed effective on 1st student's the attention?

1.1.3.Are individual and group activities performed effective on 2nd student's the attention?

1.1.4.Are individual and group activities performed effective on 3rd student's the attention?

\subsection{Purpose of Study}

Purpose of this activity is to evaluate the effect of strategic intelligence games on student's attention gathering levels.

\subsection{Importance of Study}

General purpose of this study is to examine the effect of strategic intelligence games that are played individually and as group on the duration of attention.

Therefore, it is considered that result of the study is important in terms of below issues.

1. It is important that it creates an alternative method for teachers working in the field of research field to increase student's attention time.

\subsection{Premises}

Strategic games support attention. Strategic games used in the research aim at developing attention gathering.

\subsection{Restrictions}

Qualitative research method

Subjects who are taken under the scope of study are the students who voluntary participated in intelligence games activities.

Subjects who are taken under the scope of study are selected among upper socio-cultural level.

Study comprises students who have different efficacy, age and gender features.

Study is restricted to the data obtained from 3 students of 2014-2015 academic year, who have different levels of game playing activities. 


\subsection{Respondents}

Respondents are 3 students who have different Bender Gestalt visual perception fault point in terms of levels of attention in accordance with the analysis of ÇDDÖ-TV and Canner's Teacher Rating Scale based on students subject to study among 10 students who participated in intelligence games activities of a private primary school in 2014-2015 academic year.

\section{Method}

In this study, detailed and in-depth data collection, directly collecting information on individual perceptions, experiences and viewpoints of respondents, understanding their current state and qualitative research approach in order to explain [2]. In the study, case study method is employed. The most typical characteristic of special case method is that it focuses on a current case, event, circumstance, individual and groups and tries to make indepth research. That means, it is tried to study the circumstances in detail without having any prejudice relevant to the subject of research. In the study, each subject is examined as a unit (example case-event) [4].

\subsection{Data collection tool}

\subsubsection{Bender-gestalt visual motor perception test}

Test forms are developed by Wertheimer for the first time in 1923 in order to indicate the principles to perceive Gestalt psychology. Bender adopted the shapes in certain amount in 1938 and used them as visual-kinetic test. Test-retest reliability of the test applied to the children of 5 years- 6 months and 10 years- 11 months age was applied to the students attending the years 1, 2 and 3 two times in the interval of one month with Bender Test, Pearson Moments Multiplication correlation coefficients was found as 80 for year 1st, 73 for year 2 nd and 81 for year 3rd students.

Point scoring of BG is made based on the faults in the copied shapes. Nine shapes are evaluated in terms of errors in deformation of shape, unification, turning and failure to stop and 1 fault point score is given for each error. In this study, total of fault points scores obtained from nine shapes.

\subsubsection{Conners teacher rating scale -28 (CÖDÖ-28)}

CÖDÖ-28 which is the prior short version of Conners teacher rating scale is a scale comprised of 28 articles that allows teachers to assess the behaviors of students based on their observations in their behaviors in the classroom. Adaptation works in our country are performed by Dereboy et al. [5]. In the primary schools within the boundaries of the province of Ankara, as a result of Basic Constituents Analysis applied to the data obtained from assessment of 738 girls and 795 boys making total 1539 students aged between 5-13, it is established that CÖDÖ-28 has a structure comprised of four factors and such factors are conceptualized as "Behavior/Hyperactivity/Rashness", "Lack of Attention/Difficulty in Learning", "Failure to Socialize" and "Failure to Maturing/Passivity". While total item correlation of items of the scale varied between 0.27 and 0.74 , Cronbach alpha coefficient yielded from the whole scale is 0.95 . Dereboy et al. [5] advised in their later studies that CÖDÖ-28 has three factored structure that are Lack of Attention, Hyperactivity/Rashness and Oppositional Defiant Disorder. In this study, four factored structure of the scale is used. 


\subsubsection{Child's behavior rating scale (ÇDDÖ)}

ÇDDÖ is developed in order to evaluate basic or transactional behaviors of children and translated into Turkish by Diken [6]. In ÇDDÖ, there are 7 articles evaluating transactional behaviors of child 5 of which are likert type [6]. In that context, there are articles of attention, continuity, participation and cooperation under the title of Attention and there are articles starting, common attention and sensual state [6]. In this study, articles under the title of attention are examined.

\subsubsection{Collection of data}

In the study, beginning point of data collection is the examination of literature. Than games and features used in the study are examined in terms of features. By turning the research into application and collecting the data in that way, 3 students are elected for maximum diversity exemplification among 10 students 2 of which were girls who voluntarily selected intelligence games activities.

Under the scope of study that continued for 28 weeks, 10 minutes of brakes were given between 2 courses that continued for 40 minutes in each week. Between the first and 26th weeks of the activities, ÇDDÖ and CÖDÖ were applied by classroom teachers and adviser teachers and Bender-Gestalt Visual Motor Perception Test was applied by guidance counselor.

Researcher attended the activities as respondent from time to time, intervened in the circumstances that could be problem and the questions such as "What else can you do? How it can be otherwise? Is it the same? What is the missing?" in accordance with the rules of the games played in order to prevent disagreements and questions for motivation, concentration, creating other ways, continuing the attention were asked.

\section{Findings}

In the activities, a graded teaching plan hierarchic structure is created. This structure contains below three basic stages:

1ST LEVEL-Beginning Level: Involves learning the rules of games, and gaining basic information and skills.

2ND LEVEL-Medium Level: Involves making logical inferences, applying basic strategies in strategy games and playing medium level games.

3RD LEVEL-Advanced Level: Involves upper level skills and abilities such as creative thinking, analyzing, putting forward authentic strategies, assessment, generalization and to benefit from the experiences of others.

In the plan hierarchy, below gains are considered in the games.

1. Comprehends the rules of strategy games.

2. Comprehends importance of developing strategy.

3. Creates move strategies using abstract symbols.

4. Plays strategy games within gentlemanliness boundaries.

5. Develops and applies authentic strategies relevant to a strategy game.

In the games, students are expected to perform below mental activities.

In the individual games where Artic 7 pieces and RushBlock 6 pieces are used, advising the rules that on a pre-prepared pattern they can be used only for once, by directing towards thinking whether each piece will fit to target cell, it may make easier to use the tactic of exempting some. It may cause those received this instruction to track the pieces having same number of unit and to make elimination on the pieces found and to include the pieces found. Therefore, if the rules of each game have effect on using tactic, these examples may 
direct the participants to use the tactic of inclusion. Process of attention to linking shape and ground connection between the pattern and the pieces using these strategies is expected. Arctic, namely Camouflage game is cascaded with the degrees of starter at 1-12 level, junior at 13-24 level, expert at 25-36 level and master at the levels of 37-48 and Rush Block is cascaded with the degrees of started at 1-15 level, junior at 16-30 level, expert at 31-45 level, and master at 46-60 level from the simple to the difficult order. In the study, Block and Colours games are comprised of planning, designing and shaping, Arctic and Road Block games are designed where there is guidance and pattern, Chess, Qourdidor and 123 Games are the games where assessment is made considering the result of acts of other individuals and here these games can be completed in 20 minutes of time after making certain judgment and comparison.

The game Colours has the features of spatial visual perception test. Again, it has the features that require giving depth and making trials and comparisons in order to create the visual in the pattern book. Colors is graded from easy to difficult with starter at 1-25 level, junior at 26-50 level, expert at 51-75 level and master at 76-100 level.

In the booklet Number 3, there are patterns of 40 games at each of 1 st beginner, $2 \mathrm{st}$ intermediate and 3rd advanced level and it is a game that includes four operations from easy to difficult.

Yup have the features that develop concentration that require shadow, projection and differentiating the different ones. In that line, the classroom where the activities are realized has $47 \mathrm{~m}$ area in terms of physical features and there are 18 small student desks and chairs and teacher's desk and chair, 24 pieces of wall mounted square and rectangle closed cabinets in yellow-green colors, 2 pieces of dark blue chalkboards and blackboard with white pencil. Illumination is white light and room temperature is 26 degrees. Games that are placed on the desks are fixed and it is tried to ensure that students play the games in turn. At the beginning it is tried to ensure that the student comprehend the rules of the games, importance of strategy is explained and they guided to develop an authentic strategy and participate in the games in gentlemanlike manner. Counselor's observations are indicated as below. In general, students came to the application classroom before the hour of activity. They continued the games during relaxation time of 10 minutes. They gave brake only for water and need to use the toilet. Other students who have not preferred the activity came and played games during relaxation break. Students took notes on the chart in order to follow the level advancements in the games. They asked the help of teacher for the disagreements in group play and they agreed on the solution. Loosing and gaining students congratulated each other and passed to other game. Students selected the games to play not as an obligation by voluntarily. At the half of second session of 40 minutes, students who have not preferred games performed the activities such as origami, picture drawing, cut and paste. When games are completed the pieces were collected by the game players. Each student sometimes has not preferred to play game with rules, they made creative construction works with small and big piece legos. In the program activities, start is made with 50 to 250 piece puzzle works. When interest in the completed puzzles was ended it was continued with box games. Tombola, battleships, paper pencil activities, Sudoku, jenga were also played in the activities. Twister game also became one of the games preferred by each course group. While tombola game was played with the group, there was no student who wanted to pass to other games and it was played during 2 hours of course.

The students were given activity assessment form and self assessment was asked for their own games. 8 students stated that intelligence games were their first choice. Regarding the reason to participate in the activities, 5 students stated that they played since they found it enjoying. As the most important contribution of attending these activities, the students said to be helping each other and behaving good to each other, and a student said "this is an important activity since we made teamwork". And among other responses there are "we 
should not break the heart of our friends" "my intelligence increased", "my intelligence developed", "I became more intelligent" "I became wiser", "It helped me to be more respectful". Students gave no indication on their attention however, when observations of the researchers are looked, it is observed that they also indicated development regarding the attention.

Table 1. Student conner's teacher scale attention articles pre and last test totals

\begin{tabular}{lll}
\hline Student & pre test & Last test \\
\hline A & 27 & 21 \\
B & 10 & 9 \\
C & 22 & 15 \\
D & 9 & 4 \\
E & 6 & 3 \\
F & 25 & 18 \\
G & 9 & 9 \\
H & 17 & 9 \\
I & 0 & 0 \\
I & 17 & 16 \\
\hline
\end{tabular}

Despite the points of $14-17$ for ages 5-8 and 17 point and above for the ages 9-13 indicate the lack of attention, the aim is not to make a diagnosis but to indicate the positive effect of strategic intelligence games on the student's attention. In Table 1, observations of the classroom teachers on student's school life activities and total attention points created as a result of pre and last test results indicate decrease.

Items here assess the grade given by the child to the activity. It is considered that source of increase in the Table 2 where total average of attention, persistence, participation and cooperation is indicated is intelligence games. Child may participate in a game actively or not and is assessed as high attention during activity. Quality of attendance of the child may indicate participation or non-participation in the activity to be interested or not interested. In other words, the child may seem to enjoy the activity or may not be seen so, a child who is assessed to pay low interest may participate the activity for short term; than the child may physically leave there or return to another activity for short time. When a child give very low attention to the activity, the child may change the activity frequently or may turn towards another activity, the child does not seem certainly to participate in the activity for more than a few minutes. According to ÇDDÖ which makes assessment as 1 very low, 2 low, 3 fairly good, 4 high and 5 very high, there seems a trend towards higher level of attention.

Table 2. Child behaviors assessment scale pre and last test average

\begin{tabular}{lll}
\hline Student & Pre test & Last test \\
\hline A & 2 & 2,5 \\
B & 2,5 & 3,75 \\
C & 3 & 3 \\
D & 1,75 & 2,5 \\
E & 3 & 3,75 \\
F & 2,25 & 3,5 \\
G & 2 & 3,5 \\
H & 1,5 & 3,25 \\
I & 3,5 & 3,75 \\
I & 2,5 & 3 \\
\hline
\end{tabular}

7 years 5 months of age student A who was subject to Bender - Gestalt visual perception motor test exhibited a good mental performance at the level of 10.5 age with 1 fault point. When sensual indicators of the same test are examined, it is established that this student sometime may experience confusion and burst of anger sometimes. 
When student A entered in the classroom in the first 15 sessions he was in negative dialog with his classmates, this reduced as time passed and it was observed that severity of the arguments decreased. In all individual games, Colour Code, Road Block, Number, Arctic game playing performance was with 8,5,1,1 that were lower compare to averages $19.3 ; 9.9 ; 4.5 ; 7$. He wanted to be in group games and shown the behavior of leaving the game in case of disagreements; and such behaviors hinder decision making in game and starting the attention and continuing the game and sensual process of concentration control. The student who rather concentrated in creative Logo works had disagreements with classmates with regard to sharing small piece legos with the classmates. However, behavior of complaining was observed to reduce in the last sessions of the activities. It was observed that the student created three dimension toys by making paper cutting, ornament, folding, pasting in the second half of the lesson in which individual and group games were not played. The student who tended to spend free time rather than games with rules showed an improvement of half point compare to observation scale as observed by ÇDDÖ counselor and his attention that was low came close to fairly good. Attention ÇDDÖ scale that may derive from the interest in the games was 27 at the beginning of activities that can be considered to have lack of attention reduced to 21 point at the end of the term that can be considered as improvement. During the program, the student made 1st Stage beginning gains of the games.

7 years of age 6 months old Student B who was subjected to Bender - Gestalt visual perception test made no error and exhibited a mental performance above 10.5 years of age cognitive level. It was observed that the student worked carefully during performance of test and that he ordered the shapes drawn.

Student B approached each game with interest during the time of activities, however preferred to make creative works with small lego parts in 14 of $28 \times 2$ sessions. During the lego works, the only cases he lost the attention were experienced during the sharing the parts with the friends. Student who went up to the most advance level in individual games and solved the problems in short time exhibited performance with the level of $48 ; 19 ; 13 ; 5$ that was the top of the average that was at the level of 19.3;9.9;4.5;7 in terms of game playing averages for Colour Code, Road Block, Number, Arctic games. Success of the student was at the highest level in group games. Interest of the student in games involving rules and password was observed. Attention point of the student who had interest in both individual and group games and creative game activities increased to the upper level of 3.75 compare to the observed scale of 2.5 according to CDÖD counselor. Besides game activities, CDÖD scale of the classroom teacher was 10 at the beginning of the activities and reduced to 9 that can be considered at improvement. During the program, the student made 2nd Stage medium grade gains of the games.

9 years of age 8 months old Student $C$ who was subjected to Bender - Gestalt visual perception test made 1 error and exhibited good mental performance with cognitive level of 10.5 years of age. When sensual indicators of the same test were observed, it is established that this student sometimes acted without thinking.

Student $\mathrm{C}$ attended all first $28 \mathrm{X} 2$ session activities. While acting as the leader in the classmate relations, the student exhibited positive behaviors that tried to make everyone content. With regard to the rules of the games, sometimes the student was observed breaking the rules, copying deriving from jokes or efforts to gain, and making tricks. As time passed, it was observed that situation decreased with decrease in the severity of arguments. The student exhibited performance at average or close to the average with the levels of 20;8;3;5 compare to the Colour Code, Road Block, Number, Arctic game playing averages of $19.3 ; 9.9 ; 4.5 ; 7$. The student wanted to attend group games and observed to leave the game in case of disagreements, this situation hinders deciding the game and starting the attention and continuing the game and managing sensual processes of concentration 
control. The student who rather concentrated on creative lego works had no disagreement with the classmates with regard to sharing small piece legos with the classmates. However, decrease in the behavior of complaining was observed in the last sessions of the activities. It was rarely observed that the student created various three dimensioned creative toys by making paper cutting, adorning, folding and pasting in the second half of the course in which individual and group games were not played. Student who rather preferred rule involving games shown lower development in terms of persistence but development in terms of cooperation. According to CDDÖ Counselor teacher observation scale, the attention was at medium level in terms of advancement or regression considering total points, however attention CDÖD scale in daily school life activities was 27 points at the beginning of activities indicating lack of attention and it decreased to 15 points at the end of term that mean improvement. During the program, the student made 1st Stage beginning gains of the games.

\section{Conclusion}

In terms of CDÖD scale of the students who played strategic intelligence games individually and as group; it is observed that all students shown 1 point decrease in with regard to individual behaviors such as dispersed attention and persistence, woolgathering, completion of work started, to act as if being of a smaller age, to be afraid of difficulties immediately, difficult learning; and not to be included in group of friends, to be easily directed by other children, helping each other and cooperating with the teacher and very few cases of staying at the same level were observed and consequently it is concluded that there exists a development. Again, increase in average scale points that comprised of attention, persistence, participation and cooperation under the sub title of ÇDDÖ attention supports the view that it is derived from the effect of the games.

\section{Recommendations}

More than one observes may attend these studies in order that attention developing game observations can be versatile and have multiple viewpoints.

Observations outside the school may also be included in these studies together with the parents and activities may create value for the family by playing jointly.

Video and audio records of the activities may strengthen observation assessments.

Development may be proved by applying sub tests of intelligence tests measuring the attention before and after application of activity plan.

A special warning system can be found to keep the students adhered to the subject and to obey the rules.

Activities that require high and low energy may be applied in order.

Attention may be kept by asking students "what else can be done?" rather than saying "be careful".

\section{References}

1. Auerbach, S. (2008). Anne babalar için çocuk yetiştirmede oyunun önemi (Importance of games for parents in child growing). 1st Edition, İstanbul: Yakamoz Yayıncilık.

2. Büyüköztürk, Ş., Çakmak, E. K., Akgün, Ö. E., Karadeniz, Ş. \& Demirel, F. (2009). Bilimsel araştırma yöntemleri (Scientific research methods) (3rd Edition). Ankara: Pegem Akademi. 
3. Çakmakçı, F. (2012). Dikkat eksikliği ve hiperaktivite bozukluğu öğretmen kitabı (Lack of Attention and hyperactivity disorders teacher's book), Ankara: Nobel Yayıncilik.

4. Çeliköz, N. (2001). Bir açık-uçlu öğrenme uygulaması olarak hypermedya (WWW) ortamlarında öğrencilerin proje etkinliklerinin incelenmesi (Assessment of student's project activities in hypermedia (WWW) as an open-ended learning application, Ankara: H.U. Institute of Social Sciences (Unpublished Doctorate Thesis).

5. Dereboy, Ç., Şenol, S., Şener, P. et al. (2007). Conners kısa form öğretmen ve ana baba derecelendirme ölçeklerinin geçerlikleri (Validity of Conners Teacher and Parent Rating Scales). Türk Psikiyatri Dergisi (Turkish Psychiatry Journal), 18, 1-12.

6. Diken, Ö. (2009). Ebeveyn davranışını değerlendirme ölçeği ve çocuk davranışını değerlendirme ölçeği'nin geçerlik ve güvenirlik çalışmaları (Validity and confidence studies for parent behavior evaluation scale and child behavior evaluation scale), Doctorate Thesis, Eskişehir: Anadolu University. 